\title{
La disputa política entre Calarcá-Quindío y la empresa de Fomento y Colonización Burila (1886-1908), una mirada a la construcción territorial del Estado colombiano*
}

\section{Resumen}

Este artículo pretende contribuir al estudio del proceso formativo del Estado colombiano analizando los conflictos entre la Empresa Burila, los colonos y las burocracias locales de Salento y Calarcá por los terrenos baldíos destinados para colonizar la región nororiental de la Provincia del Quindío. La pertinencia del caso radica en que permite analizar el uso e instrumentalización de la normativa agraria con la que se regulaban las colonizaciones y se adjudicaban tierras entre el siglo XIX y XX, mostrando cómo la formación del Estado no solo depende de la intervención de las burocracias centrales, sino también, de la gestión de las poblaciones y los agentes de Estado en los territorios. Metodológicamente se revisaron algunas memorias de colonos, se hizo seguimiento a los pleitos judiciales que reposan en el Archivo General de la Nación y el Archivo Histórico de Cartago y se consultó las Memorias del Ministro de Industrias de 1931.

\section{Palabras clave}

Tesauro: colonización, Estado, movimiento de protesta, instituciones políticas, sociología histórica.

Autor: Calarcá.

Referencia bibliográfica para citar este artículo: Carrero Delgado, Wilder Andrés. "La disputa política entre Calarcá-Quindío y la empresa de Fomento y Colonización Burila (1886-1908), una mirada a la construcción territorial del Estado colombiano". Anuario de Historia Regional y de las Fronteras 25.2 (2020): 307-331.

Fecha de recepción: 4/09/2019

Fecha de aceptación: 3/03/2020

Wilder Andrés Carrero Delgado: Estudiante del doctorado en Historia de la Pontificia Universidad Católica del Perú. Magister en Sociología por la Universidad del Valle. Código ORCID: 0000-0002-41734110. Correo electrónico: andres.carrerod@pucp.edu.pe, andrescarrerodelgado@gmail.com.

\footnotetext{
* El presente artículo de investigación hace parte de los avances de la tesis doctoral del autor "Los conflictos por la tierra y la construcción de la institucionalidad agraria en Colombia: un análisis de las colonizaciones y los repertorios de protesta en el Quindío (1870-1930)", la cual se lleva a cabo en la Pontificia Universidad Católica del Perú. Esta investigación es financiada por la Beca Huiracocha.
} 


\title{
Political Dispute Between Calarcá-Quindío and Empresa De Fomento y Colonización Burila (1886-1908). At Look at the Territorial Construction of the Colombian State
}

\begin{abstract}
This article intends to contribute to the study of the formative process of the Colombian State, analyzing the conflicts between the Empresa Burila, the colonists and the local bureaucracy of Salento and Calarcá, due to the vacant lands destined to colonize the northeast region of the province of Quindio. The relevance of the case consists in that it allows to analyze the use and instrumentation of the agrarian regulations with which the colonization processes were regulated and lands were adjudicated between the 19th and 20th century, showing how the formation of the State depends not only on the intervention of the central bureaucracies, but also on the population management and the State agents in the territories. Methodologically, some memories of settlers were reviewed, it was done a follow-up to the lawsuits that rest in the Archivo General de la Nacion and the Archivo Histórico de Cartago, and Memorias del Ministro de Industrias of 1931 were consulted.
\end{abstract}

Keywords

Thesaurus: Colonization, State, Protest Movements, Public Administration, Historical Sociology.

Author: Calarcá.

\section{A disputa política entre Calarcá-Quindío e a companhia de Burila Fomento y Colonización, Burila (1886-1908). Um olhar sobre a construção territorial do Estado colombiano}

\section{Resumo}

Este artigo tem como objetivo contribuir para o estudo do processo formativo do Estado Colombiano analisando os conflitos entre a Companhia Burila, os colonos e as burocracias locais de Salento e Calarcá pelas terras baldias destinadas a colonizar a região nordeste da província de Quindio. A relevância do caso reside no fato que é possivel analisar o uso e a instrumentalização das normas agrárias com as quais as colonizações são reguladas e as terras foram adjudicadas entre os séculos XIX e XX, mostrando como a formação do Estado não depende apenas da intervenção da burocracias centrais, mas também da gestão da populações e agentes estatais nos territórios. Metodologicamente, foram revisadas algumas memórias dos colonos, as ações judiciais que integram o Archivo General de la Nación, e o Archivo Histórico de Cartago, e também as Memórias do Ministro das Indústrias de 1931. Colonização, Estado, agitação social, Calarcá, instituições políticas, sociologia histórica.

Palabras chave

Tesauro: Colonização, Estado, movimento de protesto, instituições políticas, sociologia histórica.

Autor: Calarcá. 


\section{Introducción}

En las últimas décadas, el regreso del Estado como objeto de estudio a las escuelas de sociología, historia y antropología, ha permitido revisitar las viejas tradiciones del pensamiento político y traer a la discusión otras propuestas de análisis que toman distancia de los postulados funcionalistas y marxistas, para mostrar cómo el Estado no necesariamente debería ser leído desde las teleologías y más bien debería entenderse como un proceso en constante construcción. ${ }^{1}$

Este reclamo de la academia contemporánea permitió que las agendas de estudio sobre el Estado y su proceso formativo pasaran a cuestionar otros ámbitos poco frecuentados, tales como el estudio del poder infraestructural, la capacidad de acción y autonomía del Estado central frente a las élites locales, la construcción de las regiones y las localidades con una perspectiva alejada de lo que P. Bourdieu denominó funcionalismo de lo peor, ${ }^{2}$ etcétera, para abrirle paso a una lectura del Estado como proceso en el que no necesariamente el éxito radica en la imposición de la fuerza, sino más bien, en la articulación de fuerzas y tensiones que se van tramitando según las necesidades de los territorios.

Para el caso colombiano, esta tendencia no ha sido ajena, mas cuando el estudio del Estado y su proceso de formación lo han liderado teóricos de la sociología y la historia política que propusieron interpretar la violencia armada como el principal eje de construcción de institucionalidad. ${ }^{3}$ Sin embargo, las limitaciones para explicar las múltiples formas de configuración que tienen los Estados, junto con la crítica hecha por autores como M. Mann en relación con la sobrevaloración de la misma historia europea y norteamericana del Estado, ${ }^{4}$ impulsó la revisión de las experiencias nacionales y con ello, la puesta en circulación de nuevas interpretaciones del proceso formativo del Estado colombiano, que sin desconocer los costos de la guerra, han pretendido mostrar otras formas de relacionamiento entre la política, la sociedad civil, el mercado y la violencia. ${ }^{5}$

\footnotetext{
${ }^{1}$ En el 2007, con financiación del Gobierno Nacional de Argentina, se publicó una selección de ensayos sobre el Estado y las agendas de discusión para el siglo XXI las cuales pretendieron no solo dialogar con la tradición política y sociológica del Estado, sino también, introducir nuevas propuestas interpretativas que utilizaron como base la crítica al funcionamiento de las burocracias, promoviendo perspectivas que no se circunscribieran exclusivamente a la guerra como un elemento de cohesión. Para ampliar esta discusión véase: Carlos H. Acuña (Compilador), Lecturas sobre el Estado y las políticas públicas: retomando el debate de ayer para fortalecer el actual (Buenos Aires: Gobierno de Argentina, 2007).

${ }^{2}$ Pierre F. Bourdieu, "Clase del 18 de enero de 1990", Sobre el Estado: cursos en el Collège de France (1989-1992) (Barcelona: Anagrama, 2014) 17.

${ }^{3}$ Para una ampliación detallada de las teorías sobre el proceso formativo del Estado en Colombia con sus respectivas fortalezas y debilidades, véase: Fernán E. Gonzáles Gonzáles, "El proceso de formación estatal en Europa e Iberoamérica", Estado y poder en Colombia (Bogotá: Odecofi, 2014).

${ }^{4}$ No solo en su clásica obra sobre las Fuentes del Poder, ya Mann venía mostrando la necesidad de superar las teleologías con las que se ha estudiado al Estado. En sus reflexiones sobre otras experiencias, el caso colombiano y latinoamericano también tuvo acogida, para ello ver: Michael Mann, "The crisis of the Latin American Nation-Satate, The political crisis and internal conflict in Colombia Abril 10-13 (Bogotá: Uniandes, 2002).

${ }^{5}$ Se destaca la teoría propuesta por Fernán González y el equipo de Odecofi con la cual se habla de una presencia diferenciada del Estado en el tiempo y el espacio, lo que quiere decir que para estudiar la
} 
Es por ello que, retomando las bases teóricas propuestas por las nuevas corrientes interpretativas del Estado, hemos considerado pertinente ampliar el campo de estudio utilizando otras unidades de análisis y temporalidades que permitieran mostrar que el Estado no solo cristaliza en contextos de guerra, sino también, en la interacción entre población y burocracias locales con burocracias regionales y nacionales; entendiendo por cristalización, la materialización de un tipo de Estado con múltiples aristas que se producen luego de tramitar un conflicto.

Para tal fin, se seleccionó como unidad de análisis los conflictos derivados de la colonización de la Provincia del Quindío en el tránsito del siglo XIX al XX, y para facilitar el diálogo con la teoría, se estudió el caso de Calarcá-Quindío y la disputa por las tierras baldías en la frontera norte de la Empresa de Fomento y Colonización Burila.

La pertinencia de este caso radicó en que no solo estaba completo, es decir, que era posible consultarlo por la disponibilidad de los documentos primarios, sino también, porque nos permitió ver cómo funcionaban las burocracias locales y cuál era su relacionamiento con la población y otros cuerpos o unidades de Estado encargadas de la administración del territorio. De igual manera, el estudio de los conflictos entre Calarcá y Burila nos permitió evidenciar la fragilidad del Estado central frente al poder y autonomía de las burocracias locales y regionales, aunque también, dicha fragilidad sirviera para mostrarnos cómo estas burocracias podían instrumentalizar el discurso estatal para garantizar no solo el beneficio propio o de sus poblaciones, sino también, para materializar el discurso del Estado promovido en la Constitución, leyes, sentencias de la Corte y discursos del Ejecutivo ante el Congreso de la República.

En tal virtud, el presente artículo tiene como objetivo principal contribuir al estudio del proceso formativo del Estado colombiano a partir del estudio y análisis del relacionamiento entre burocracias y población durante los conflictos por la colonización de las tierras baldías reclamadas por el actual municipio CalarcáQuindío y la Empresa de Fomento y Colonización Burila. Como objetivos específicos se pretende:

- Estudiar el proceso formativo del Estado en Calarcá-Provincia del Quindío, a partir de la propuesta hecha por Óscar Oszlak y Guillermo O`Donnell, en la que se entiende al Estado como un entramado de institutos que en algunas ocasiones pueden competir entre sí o interactuar con otros grupos sociales con capacidad de oposición, rechazo, acatamiento o transformación de las ideas emitidas desde el centro, y no precisamente como un cuerpo compacto u homogéneo.

- Analizar las estrategias de acción política desplegadas por los colonos y agentes de Estado de Calarcá-Quindío durante la colonización y disputa con la empresa Burila por la propiedad de la tierra ocupada para la fundación del municipio, y

historia del Estado colombiano, es menester partir considerando que hay una "manera diversa como las instituciones estatales se relacionan con las diferentes regiones y las redes de poder realmente existentes en ellas, según sus particularidades, su tipo de poblamiento y el grado de cohesión y jerarquización social que hayan alcanzado", en: Fernán E. Gonzáles Gonzáles 60. 
- Promover la reflexión de las historias regionales y locales, con el fin de fortalecer y ampliar las perspectivas sobre el proceso formativo del Estado en Colombia.

En cuanto al abordaje teórico, consideramos que es menester volver la mirada hacia el estudio de las burocracias locales, la recepción del discurso estatal en los territorios y la instrumentalización de las leyes por parte de las poblaciones y las organizaciones sociales; para ello, partimos de la idea de que el Estado no debe estudiarse como un todo homogéneo; más bien, debe reconocerse las particularidades históricas de los territorios y sus conflictos, entendiendo que éstos se han tramitado de manera discontinua en relación con los postulados o directrices dadas por el Estado central, por lo que la adopción de la legalidad como eje o direccionamiento para tramitar los conflictos esta dada por la practicidad que la misma institucionalidad ofrece a la hora de desatar los nudos ${ }^{6}$ de la vida social.

Bajo esta perspectiva, no necesariamente queremos deslegitimar la tradición estructuralista y funcionalista que ha liderado el estudio del Estado, pero sí buscamos tomar distancia al reconocer que para estudiar el Estado no son suficientes las teleologías, o incluso, las miradas institucionalistas del Estado como modelador de las regiones a partir de la tesis del despliegue del Estado, que si bien, nos serviría inicialmente para reconocer la capacidad de las burocracias locales en la operacionalización del discurso institucional, quizá nos quedaría limitada para explicar cómo participaban personas de la vida local ajenas a la administración. ${ }^{7}$

Por ello, y pretendiendo defender la idea inicial del proceso formativo del Estado, nos sostenemos en que, más allá de un despliegue del Estado, nuestro caso de estudio permite ver no solo las discontinuidades, es decir, la posibilidad de que los conflictos sean, o no, tramitados bajo la égida de la formalidad vigente, sino también, los reveces en la planificación y administración de los territorios. ${ }^{8}$

\footnotetext{
${ }^{6}$ Entiéndase desatar los nudos desde la perspectiva de María Emma Wills Obregón, expuesta en María Emma Wills, "Los tres nudos de la guerra colombiana: un campesinado sin representación política, una polarización social en el marco de una institucionalidad fracturada, y unas articulaciones perversas entre regiones y centro", Centro Nacional de Memoria Histórica, en: https:/www.ambitojuridico.com/ BancoMedios/Documentos\%20PDF/los-tres-nudos-de-la-guerra-colombiana-1447173574-1460381073. pdf.

${ }^{7}$ Una de las principales particularidades de los conflictos durante las colonizaciones en la Provincia del Quindío tiene que ver con la intervención de actores sociales que no están reconocidos en la legislación nacional como intermediarios o negociadores. Este es el caso de curas y 'notables del pueblo' que, apoyados en el poder simbólico de daba su cargo y el capital social convertido en redes de apoyo, lograban un diálogo directo con autoridades regionales y nacionales, abrogando con ello por una mayor atención para los casos de alta sensibilidad. Para estudiar experiencias de este tipo, ver: Nancy Appelbaum, Dos plazas y una nación: Raza y colonización en Riosucio, Caldas, 1846-1948 (Bogotá: Instituto Colombiano de Antropología e Historia ICANH, Universidad de los Andes, Universidad del Rosario, 2007).

${ }^{8}$ Una paradoja, si se quiere leer de esta manera, tiene que ver con delegar poder a los concejos municipales para que administren las adjudicaciones. Lo es, en tanto la política de la Regeneración, que es el periodo estudiado, tenía como objeto la centralización de la administración de lo público y con ello, los baldíos; por tal razón, no era consecuente que el control de las adjudicaciones pasara a los concejos municipales; lo que ocurrió con la emisión del decreto ejecutivo 27 de 1906, el cual, en su artículo 6 delegaba la autoridad a los concejos municipales para exigirle a los cultivadores de más de 100 hectáreas, que probaran el trabajo en los cultivos y por lo tanto, pudieran reclamar así el derecho a una adjudicación (AGN, Colombia,
} 
Para justificar nuestra propuesta analítica elegimos dos categorías que guiaron la reflexión del conflicto entre la Empresa de Fomento y Colonización Burila, los colonos y la burocracia de Calarcá: la primera fue 'autonomía de las unidades de Estado', pues consideramos que las burocracias no tienen un diálogo exclusivo con ellas mismas; por el contrario, su funcionamiento está dado por las relaciones que se construyen entre las unidades y las poblaciones, poblaciones y gremios, gremios y unidades, y así sucesivamente en un constante entramado.

Siguiendo a Oszlak y O'Donnell, ${ }^{9}$ entendemos por unidades las secciones en las que se divide el Estado, es decir, los cuerpos administrativos del poder o institutos; por lo que, y a pesar de las jerarquías institucionales, las acciones e intervenciones de una unidad podrán ser tramitadas por los agentes que pertenecen a otras unidades, distorsionando o acatando las ideas iniciales según sus intereses. De igual forma, cada enunciación de una jerarquía con fines de implementación tendrá una alta probabilidad de tensión en el territorio, más cuando se trata de una decisión que pretende el cumplimiento por vía de otra unidad de igual o menor jerarquía; por ejemplo, una resolución de un ministerio puede encontrar opositores con capacidad de presión y control en una oficina estatal de una población.

Aprovechando la propuesta hecha por Oszlak y O'Donnell, y con la intención de ampliar su mirada, consideramos que las acciones del Estado son producto de una racionalidad administrativa, es decir, el Estado interviene o deja de hacerlo siempre y cuando la participación haya sido reflexionada y cuente con una probabilidad de éxito. Esto quiere decir que el Estado no interviene a menos que sea necesario, pues sus agentes miden los costos de la acción.

Ahora bien, debido a su división en unidades, la intervención debe entenderse también desde esta lógica; es decir, puede haber acciones de Estado de orden nacional, como también regional y local, y no necesariamente se deben unas a otras. Por ello, para los autores, las políticas estatales son un "conjunto de acciones y omisiones que manifiestan una determinada modalidad de intervención del Estado en relación con una cuestión que concita la atención, interés o movilización de otros actores en la sociedad civil". ${ }^{10}$

La segunda categoría usada fue la de 'repertorios de acción política', la cual se entendió como aquellas acciones racionales con arreglo a fines, en el sentido Weberiano, ${ }^{11}$ materializadas en demandas, misivas, memoriales, denuncias, etc., hechas

1906, Diario Oficial N. 12621 del 18 de abril. Decreto ejecutivo 27 de 1906). Como era de esperarse, las reclamaciones por extralimitación y corrupción de los concejos llevó a que el Gobierno derogara tal disposición administrativa y la adjudicación de baldíos volviera a la oficina del ministerio de Obras Públicas (AGN, Colombia, 1907, Diario Oficial N. 12986 del 27 de junio, Ley 36 de 1907).

${ }^{9}$ Óscar Oszlak y Guillermo O`Donnell, "Estado y políticas estatales en América latina: hacia una estrategia de investigación", Lecturas sobre el Estado y las politicas públicas: retomando el debate de ayer para fortalecer el actual. Comp. Carlos H. Acuña (Buenos Aires: República de Argentina, 2007).

${ }^{10}$ Óscar Oszlak y Guillermo O`Donnell 565.

${ }^{11}$ Max Weber, “Conceptos sociológicos fundamentales”, Economía y Sociedad, vol. 1 (Barcelona: Fondo 
por individuos, colectivos y agentes de Estado en representación de una unidad, y que tienen como objetivo confrontar una disposición administrativa, reafirmar un discurso de Estado, oponerse a un enemigo común, crear un opositor, etc. Estos repertorios de acción son políticos porque se sustentan en principios de racionalidad, medición de la acción, planificación y organización de la estrategia. ${ }^{12}$

Hacer uso de estas dos categorías nos permitió ubicarnos frente a la capacidad de gestión que tenían los agentes de Estado y los privados, fueran estos civiles o funcionarios de Burila; ahora bien, esta gestión o acción política se materializaba constantemente en los repertorios enunciados previamente, por lo que la respuesta que daba la institucionalidad por medio del fallo judicial o la resolución administrativa tenía un impacto inmediato en el diseño y transformación del territorio, y consigo, de las políticas del Estado para formalizar el proceso de colonización en Calarcá e incluso, en la misma provincia. ${ }^{13}$

Metodológicamente se construyó una matriz de análisis documental que confrontó las categorías de estudio con los hallazgos en los documentos de archivo. Teniendo presente que las dos categorías centrales fueron 'autonomía de las unidades de Estado y 'repertorios de acción política', ambas se fueron desarrollando a partir de las fuentes secundarias, especialmente siguiendo la propuesta de Fernán González, y también la interpretación del Estado y la autonomía de las unidades dada por Óscar Oszlak y Guillermo O`Donnell.

Ahora bien, para la categoría 'autonomía de las unidades de Estado', con la que se defiende la hipótesis central, se cruzaron los informes y memoriales enviados desde los concejos municipales, las alcaldías y el personero municipal de Salento, con las respuestas obtenidas en las unidades de rango superior como los ministerios. En cuanto a la categoría de 'repertorios de acción política', esta se desarrolló a partir de la clasificación y análisis de las memorias de pobladores sistematizadas en la página http://calarca.net, y los procesos judiciales adelantados por los colonos en contra de Burila y que reposan en el Archivo General de la Nación.

Para corroborar el alcance que tuvieron estos repertorios de acción, se hizo un seguimiento detallado del conflicto, identificando la primera acción política hasta el cierre del pleito con la resolución emitida por el Ministerio de Industria a favor de Calarcá. Estas fuentes reposan en el Archivo General de la Nación y la Biblioteca del Congreso de la República- Luis Carlos Galán Sarmiento.

\footnotetext{
de Cultura Económica, 1974) 127-130.

${ }^{12}$ Hanna Arent, ¿Qué es la política? (Barcelona: Paidós, 1997).

${ }^{13}$ La disputa por las tierras del valle del río La Vieja no era nueva, puesto que desde la fundación de la empresa Burila, varios colonos habían comenzado pleitos en contra de la empresa por haberse apropiado de una vasta extensión de terrenos baldíos con ocupantes y posesiones; de allí que el resultado de los pleitos hubiera sido considerado por el Personero de Calarcá como un antecedente para anticiparse a reclamar ante el Gobierno nacional diciendo que si bien, no conocía el desenlace, lo suponía adverso para los colonos; en: AGN, Colombia, 1889, Fondo Ministerio de Fomento, Sección República, Serie Baldíos, Volumen 1, Tomo XI, Folio 111.
} 
Una de las dificultades durante la construcción de este estudio fue el volumen de información consultada que posteriormente tuvo que seleccionarse; como también, la limitación de tiempo y espacio para compartir las experiencias más relevantes del proceso entre Burila y Calarcá. También se resalta la poca circulación de fuentes secundarias dedicadas a la sociología histórica que hagan uso de los conflictos agrarios como unidad de análisis para el estudio del proceso formativo del Estado, lo que impide crear referentes o modelos de estudio y explorar otras alternativas interpretativas.

Finalmente, se resalta que este estudio de caso hace parte de los ejemplos seleccionados en la construcción de la investigación "Los conflictos por la tierra y la construcción de la institucionalidad agraria en Colombia: un análisis de la colonización y los repertorios de acción política en la Provincia del Quindío (1870 - 1930)", con la cual se pretende obtener el título de Doctor en Historia en la Pontificia Universidad Católica del Perú.

\section{El contexto}

La Provincia del Quindío comenzó a participar en la agenda republicana, en parte, por tratarse de un territorio que fungía como tapón natural entre el centro y suroccidente del país, pero con un alto potencial para la movilidad de mercancías en relación con el otro camino nacional que cubría la ruta Pitalito-Huila - PopayánCauca. ${ }^{14}$

Esta situación había sido identificada por Simón Bolívar desde que cruzó el Camino del Quindío, de allí que promoviera su rehabilitación a través de estímulos financieros tales como la adjudicación de peajes para quienes habilitaran la vía y garantizaran su mantenimiento; por lo que a mediados de siglo XIX, el gobernador del Cauca, Jorge Juan Hoyos Cabal, asumió el liderazgo en su recuperación y promovió la fundación de la colonia penitenciaria de Boquía, posteriormente distrito de Salento; todo con el fin de garantizar comida y asistencia a los viajeros y comerciantes que se desplazaban entre Bogotá y Cartago. ${ }^{15}$

Puesto que el impulso colonizador tenía como fin, promover fundaciones a la vera del camino; a partir de 1840, año en los que se iniciaron las obras en Boquía, fueron también apareciendo nuevos asentamientos como la actual Salento (1842), Pereira (1863), Filandia (1878), Circasia (1884) y claro está, Calarcá (1886), las cuales se veían beneficiadas por el capital y las personas que hacían uso del Camino y pernoctaban, además de las adjudicaciones de baldíos a quienes formalizaran las colonizaciones del territorio. Esta colonización tuvo como principal característica, combinar el tipo de colonización dirigida la cual fue llamada por Alonso Molina como

\footnotetext{
${ }^{14}$ Larry Vito Larrichio, La construcción multicultural de una economía colonial: cambio demográfico y organización del trabajo en el Valle medio del río Cauca, siglo XVIII (Pereira, Universidad Tecnológica de Pereira, 2018).

${ }^{15}$ Alonso Molina, El despliegue del Estado en el poblamiento de la Montaña del Quindío y la fundación de Santa Rosa de Cabal, 1840-1845 (Pereira, Universidad Tecnológica de Pereira, 2019).
} 
“despliegue del Estado en el poblamiento de la montaña del Quindío", con el más común de la región, es decir, la espontánea.

De todas formas, entre 1840 y 1880, la Provincia no logró un importante crecimiento poblacional, en parte porque el siglo XIX colombiano no ofrecía garantías tales como estabilidad jurídica, financiera y poblacional; esta última en parte por las guerras civiles y la calidad de vida; por lo que durante el periodo en mención, la Provincia solo logró tener 6 distritos y 8 caseríos, siendo Salento el único ubicado hacia la zona nororiental y por ello, fundamental para el desarrollo del poblamiento y formalización de las tierras ocupadas en los valles de los ríos Quindío, La Vieja y Barragán.

Tabla 1. Relación administrativa y de distancias de las poblaciones de la Provincia del Quindío a $1878 .{ }^{16}$

\begin{tabular}{|c|c|c|}
\hline $\begin{array}{l}\text { Capital del Municipio o punto de } \\
\text { partid a }\end{array}$ & $\begin{array}{c}\text { Nombre de las secciones } 0 \\
\text { cabeceras }\end{array}$ & $\begin{array}{c}\text { Distancia } \\
\text { en leguas a } \\
\text { Cartago }\end{array}$ \\
\hline \multirow{16}{*}{ Cartago } & Distritos & \\
\hline & Obando & 4 \\
\hline & Victoria (a) & 6 \\
\hline & Pereira & 6 \\
\hline & Sta Rosa & 8 \\
\hline & Salento & 111 \\
\hline & Maria (Villamaria) & 14 \\
\hline & Caseríos & \\
\hline & Zaragoza & 1 \\
\hline & Sta Ana (Filadelfia) & 2 \\
\hline & $\mathrm{Paz}$ & 2 \\
\hline & Gutiérrez & 3 \\
\hline & Condina (hoy desaparecida) & 7 \\
\hline & San Francisco (Chinchiná) & 11 \\
\hline & Palestina & 12 \\
\hline & Segovia & 14 \\
\hline
\end{tabular}

Pero si bien, durante cuarenta años no hubo mayor movimiento poblacional en la región, a partir de 1882, el incremento de colonos provenientes de Antioquia principalmente ${ }^{17}$, comenzaron a arribar al Quindío para tumbar la selva y hacer sembradíos con el objeto de adquirir la posesión de las tierras cultivadas y reclamar el derecho sobre los baldíos como lo promovía la Ley 61 de 1874 . Con lo que no se contaba era que, para las mismas fechas, aparecería en la escena colonizadora el

\footnotetext{
${ }^{16}$ Archivo Histórico José María Arboleda y Llorente, de la Universidad del Cauca, Colombia (AHJML1), 1878, Fondo Archivo inactivo, Sección República, Caja 145, Legajos 65-68.

${ }^{17}$ Aunque la historiografía regional ha priorizado la historia antioqueña, el Quindío también tuvo migraciones provenientes de otras regiones del país como Boyacá y Cundinamarca. Al respecto, ver: Isaías Tobasuña, "Del altiplano cundiboyacense al páramo de letras (caldas). Algunos aspectos socioculturales del proceso", (Ponencia, II simposio de Historia Local y Regional, Academias y Universidades, Universidad Tecnológica de Pereira, 2007).
} 
otro actor importante del Quindío, por lo menos en lo que tiene que ver con la franja oriental de la Provincia y lo que se ha denominado colonización empresarial; ${ }^{18}$ es decir, la Empresa de Fomento y Colonización Burila.

En la historia regional, la empresa Burila ha sido estudiada desde varias perspectivas, destacándose la obra de Olga Cadena Corrales ${ }^{19}$ como la más amplia y documentada, y estudios como los de Albeiro Valencia Llano ${ }^{20}$ que pretendieron algunas comparaciones con casos como los de la Empresa González Salazar y Compañía, relacionada con los conflictos de la zona occidental de la Provincia y su frontera con Antioquia. Desde la literatura, también es posible encontrar referencias a la empresa Burila, aunque con un evidente sentimiento de molestia por las actividades desempeñadas en el territorio y la corrupción de los agentes de Estado que tuvieron relaciones directas o indirectas con ellos. ${ }^{21}$

La empresa de Fomento y Colonización Burila se fundó en 1884 con el objetivo de "la explotación de los terrenos de Burila [...], las minas, salinas y carboneros existentes en dichos terrenos", ${ }^{22}$ y claro está, poblar los territorios comprendidos en los linderos legalizados mediante Escritura. Al fundarse la empresa, el capital inicial fue $\$ 100.000$ pesos divididos en mil acciones, y además de los intereses de explotar las minas y las salinas, se pretendía poblar el territorio para facilitar la movilidad por el Cauca; asunto prioritario para los gobiernos nacional, regional y local. Por tal motivo, el artículo 7 de la Escritura fundacional consideraba que

El logro más adecuado de las tierras i allá donde se sea que pueda empatarse las tres más [cordilleras], la del Tolima por Anaime, la del Valle del Cauca por la Paila i de Antioquia por Circacia, lo más cerca posible de la confluencia de los ríos Barragán y Quindío que juntos forman el caudal de la Vieja, conllevando las mejores condiciones de salubridad, clima i fotografía, cederá la compañía un gran lote de cuatro mil fanegadas de forma rectangular... [y] ...En el centro de ese globo de tierra se demarcará el área para una ciudad con una extensión de cuatrocientas fanegadas conforme a las indicaciones y planos que oportunamente se le pasarán a un agente que allí tratará de tener la compañía $[\mathrm{sic}][\ldots]^{23}$

Sin embargo, la incapacidad del Estado para definir los terrenos baldíos de la zona facilitó que Lisandro Caicedo, principal accionista de la empresa, pudiera alterar los linderos de la herencia dejada por su padre y así, hacerse con el vasto valle del

\footnotetext{
18 Olga Cadena, "Impacto de la compañía Burila en el Quindío", Voces, Revista de estudios sociales, 3 (1997): 57-70.

${ }^{19}$ Olga Cadena, "Procesos de colonización en el Quindío: el caso de Burila" (Tesis, Maestría en Historia, Universidad Nacional de Colombia, 1988).

${ }^{20}$ Albeiro Valencia, Colonización, fundaciones y conflictos agrarios, (Manizales: Artes Gráficas Tizán, 2000).

${ }^{21}$ Jaime Buitrago, hombres trasplantados, novela de colonizaje (Biblioteca de autores quindianos, 2011).

${ }^{22}$ Archivo Histórico de Manizales, Colombia (AHM), 1884, Fondo Notaría, Escritura 693 del 25 de noviembre de 1884, páginas 210-211.
}

${ }^{23}$ AHM, Colombia,1884, Fondo Notaría, Escritura 693 del 25 de noviembre de 1884, páginas 210-211. 
río La Vieja, Barragán y parte de las riveras del Quindío. ${ }^{24}$ Aunado a esto, y teniendo presente que otros cultivadores venían explorando el territorio, las reclamaciones por la legalidad de las escrituras y el deslinde hecho por Burila, se convirtió en el principal factor de conflicto entre la empresa, colonos, el concejo municipal de Salento, e incluso, el ministerio público representado por el Personero municipal y la Fiscalía. ${ }^{25}$

Otra de las particularidades de la Empresa fue tener entre sus accionistas, figuras de la política nacional como Rafael Reyes y Marcelino Arango; ${ }^{26}$ igualmente la integró personajes de la política regional como Pompilio Gutiérrez, posterior gobernador de Caldas y otras reconocidas personalidades de la región con suficiente poder político y económico en el territorio. Por otra parte, y quizá aquí está el elemento más innovador para el momento histórico, la compañía no solo se había fundado con un capital real que era la tierra, sino que contaba con uno ficticio que eran las acciones las cuales se vendían para hacer crecer más rápido la inversión.

Como puede apreciarse en las investigaciones hechas por Olga Cadena, la empresa operó desde 1882 hasta muy entrado el siglo XX, cuando le fue imposible sostener los pleitos iniciados por los colonos de la región en su contra. Ahora bien, no se cuenta con más información sobre esta empresa debido, entre otras, a la ausencia de archivos privados y actas de la junta de accionistas. Tampoco se han hecho estudios en profundidad sobre la compraventa de tierras y la valorización de los predios. Sin embargo, sí se sabe que la empresa fomentaba la colonización al interior del globo de tierra apoyando la escrituración de las posesiones, y facilitaba la formalización para quienes acogieran sus lineamientos. Esto conllevó al enfrentamiento entre colonos traídos por la empresa y colonos espontáneos que reclamaban sus derechos como cultivadores de buena fe un baldío nacional, tal como ocurrió en Colón, actual municipio de Pijao.

Podría decirse entonces que la Provincia del Quindío, por lo menos en lo que respecta a su zona nororiental, se caracterizó por la confluencia de tres tipos de colonización: la dirigida o estatal, denominada por Molina como "despliegue del Estado, la espontánea que consistía en la exploración autónoma de los cultivadores con el objeto de tumbar la selva y establecer un cultivo, y la empresarial, que sería la promovida por Burila. Justamente en este contexto es que aparece Calarcá, caserío que rápidamente se eleva a la condición de distrito y que tuvo que enfrentarse a la empresa por el control de las tierras de la línea norte delimitadas en el primer deslinde de 1884.

A continuación, veamos cómo fue el proceso de fundación de Calarcá y qué tipo de conflicto se dinamizó en el territorio entre los colonos, las burocracias locales y la Empresa; esto con el fin de analizar las dinámicas del proceso formativo del Estado.

\footnotetext{
${ }^{24}$ Sobre la herencia de Caicedo y el primer deslinde, ver: Olga Cadena, Impacto de la compañia Burila.

${ }^{25}$ Estos casos pueden ser ampliados en Wilder Andrés Carrero, Los procesos de formación estatal en Colombia vistos a través de la colonización y las prácticas políticas en el Quindio (1884-1930), (Pereira: Universidad Tecnológica de Pereira, 2018).

${ }^{26}$ El listado de accionistas se puede consultar en los anexos de Olga Cadena, Procesos de colonización en el Quindio, anexo 2.
} 


\section{Calarcá en la dinámica colonizadora}

La historia de Calarcá, como la de los otros municipios que conformaron la extinta Provincia del Quindío, ${ }^{27}$ tiene entre sus principales características, no solo la ampliamente estudiada colonización antioqueña, ${ }^{28}$ sino también, la conflictividad alrededor de la formalización de la propiedad rural ${ }^{29} \mathrm{y}$ el rápido enriquecimiento y valorización de las tierras abiertas a cultivo. ${ }^{30}$ Esta historia de colonización, conflictos agrarios y construcción de Estado no podría entenderse por fuera de los actores que fueron diseñando el territorio, por lo que debemos reconocer que, el hoy llamado Eje Cafetero, se debe a la confluencia de colonos y cultivadores, el trabajo de la burocracia regional y local, y la intervención de la Empresa de Fomento y Colonización Burila.

El poblamiento de Calarcá comenzó hacia 1882, y en 1886, los primeros pobladores promovieron la elevación a caserío con el fin de, a corto plazo, fundar un distrito municipal con autonomía política y financiera. Este rápido trámite para formalizar los terrenos ocupados tenía que ver con dos asuntos a saber; el primero era el aprovechamiento de la coyuntura legislativa que garantizaba la entrega de tierras baldías a quienes lograran demostrar una posesión con casa y labranza (ley 61 de 1874 y 48 de 1882), y el segundo tenía que ver con la sospecha de que la Empresa Burila había incluido en su escritura fundacional, los terrenos baldíos correspondientes a los valles de los ríos La Vieja, Quindío y Barragán; por lo que, aprovechando el respaldo político de Salento y apoyo del señor Ramón Franco, propietario del terreno donde se había dado el primer asentamiento, ${ }^{31}$ se comenzó a promover la migración de personas y se respaldó dicho programa con hechos políticos como el nombramiento de la primera junta de entusiastas; un ritual jurídico y político que tenía como fin último que la comunidad reconociera, y se reconociera, en el programa de formalización diseñado por el Estado.

En este acto iniciado el 29 de junio de 1886, participaron personalidades de la vida local de Salento y de la región tales como Pedro Osorio, Jesús María Buitrago,

\footnotetext{
${ }^{27}$ Hoy distribuidos entre los departamentos de Caldas, Risaralda, Quindío y Valle del Cauca.

${ }^{28}$ La historiografía de la colonización en el Eje Cafetero es supremamente abundante debido al mito de la colonización antioqueña iniciado por James Parsons y secundado por la mayoría de los escritores locales. Para conocer los principales estudios y rupturas sobre la colonización se recomienda revisar el libro de Carlos Miguel Ortiz Mesa y otros. Caldas, una región antigua y nueva, tradicional y moderna, local y nacional: hacia un nuevo Siglo XIX del noroccidente colombiano. Balance bibliográfico de Antioquia, Caldas y Chocó, Tomo 2, Coord., Luis Javier Ortiz, (Medellín: Universidad Nacional de Colombia, 2015). Igualmente se recomienda revisar la crítica hecha al modelo de colonización propuesto por James Parsons en Jaime Londoño, "El modelo de colonización antioqueña de James Parsons. Un balance historiográfico", Fronteras de la historia, revista de historia colonial latinoamericana, 7 (2002):187-228.

${ }^{29}$ Wilder Andrés Carrero Delgado, Los procesos de formación estatal en Colombia.

${ }^{30} \mathrm{Si}$ bien, no hay estudios sobre este asunto, sí es posible hacer un seguimiento de los precios de la tierra y la compraventa de mejoras, en el Archivo Histórico de Cartago, fondo Notaría, y el Archivo Histórico de Manizales, fondo Notaría.

${ }^{31}$ Las tierras ocupadas fueron cedidas por Ramón Franco, como consta en las memorias del municipio. Dicha sesión de terrenos se hizo 8 de septiembre de 1887. Véase Calarcá.Net, https://www.calarca.net/ enlamano.html (2019)
} 
Baltasar González y Segundo Henao, en presencia del señor Luís Tabares, quien es llamado alcalde, pero en realidad se trataba del Comisario delegado por Salento, y el secretario de la junta de entusiastas, señor Francisco Velásquez R., ${ }^{32}$ quienes revistieron con legalidad jurídica y legitimidad social el proceso fundacional.

En vista del éxito que deparaba el proyecto, el 7 de julio de 1886, los delegados decidieron emprender lo que posteriormente sería la Junta Pobladora encargada de hacer las demarcaciones del terreno, establecer las primeras rutas de poblamiento y representar a los colonos ante las instancias municipales competentes. De acuerdo con las memorias locales, el primer artículo de la Junta estableció el tamaño de la plaza y trazó las calles así:

La plaza de dicha población tendrá 100 varas, las calles 10 varas, y las cuadras 80. Los solares serán entregados por el valor de un peso de Ley. Los individuos que reciban solares quedarán en la obligación de cercar el solar, rozarlo y ponerle casa de habitación, en el prefijo término de cinco meses. El que no cumpla con lo estipulado en dicho artículo, perderá el derecho, y se le entregará a otro que pueda edificar $[\ldots] .^{33}$

Es importante mencionar este paso con el que se formalizó el asentamiento por tres razones: primero, no era suficiente con colonizar, sino que se debía legalizar la acción ante las instancias competentes y cumplir con los procedimientos exigidos por la ley; esto quiere decir que era de voz pública la necesidad de colonizar el territorio, pero con el visto bueno de la institucionalidad. Como segundo, los fundadores debían conocer los requisitos para colonizar, incluso saber que el lugar de encuentro era baldío o estaba abierto a la colonización; y tercero, más que poblar y registrar el asentamiento ante las debidas instancias, se debía conocer la jurisdicción a la cual pertenecería el área ocupada, como también, los pasos para llevar a cabo la formalización.

La colonización era una acción enmarcada en los lineamientos del Estado, es decir, había una aceptación del discurso de tal manera que las fundaciones no se hacían aleatoriamente sino con una planificación previa; por otra parte, y como se verá más adelante, la institucionalización de las prácticas de la vida cotidiana también servían para el disenso y con ello, la reclamación; de allí que colonizar no fuera una acción deliberada sino racional que podría considerarse como la institucionalización de la vida cotidiana, el reconocimiento del orden dado por el Estado, la aceptación de que el Estado es, como diría Bourdieu, el "principio de organización del consentimiento como adhesión al orden social, a los principios fundamentales del orden social". ${ }^{44}$

Puesto que durante los primeros años fueron llegando familias de cultivadores, la situación de los predios aledaños a los cedidos por el señor Franco exigían también ser formalizados, asunto que solo era posible siempre y cuando el Estado hiciera las adjudicaciones y negara el derecho de Burila sobre los terrenos reclamados por

\footnotetext{
${ }^{32}$ Calarcá.net.

${ }^{33}$ Calarcá.net.

${ }^{34}$ Pierre F. Bourdieu 18.
} 
Calarcá; lo que básicamente era un primer problema, pues para la fecha, como aún ocurre en Colombia, el Estado no sabía qué era baldío y qué era privado; además, Burila había certificado las escrituras de fundación con el visto bueno del gobierno nacional ${ }^{35}$ y por ello mismo, la suerte de los colonos recién llegados entraba en un limbo jurídico-administrativo que solo podría solucionarse por vía judicial o con una resolución ministerial que certificara la condición de baldíos de la Nación para los terrenos ocupados.

Aún así, y pese a la incertidumbre con los resultados del pleito que comenzaba a gestarse entre colonos, el municipio de Salento y la empresa Burila, el 8 de octubre de 1887, es decir, casi un año después, el caserío fue reconocido como parte constitutiva de Salento; nominación contradictoria si se quiere debido a la ambigüedad que tenían los predios, pero que en términos generales, devela la autonomía de los agentes del Estado local sobre el territorio y la planificación racional para enfrentar a la empresa; por lo que, como era de esperarse, los representantes de Burila comenzaron a interponer denuncias por la ocupación de sus terrenos, en vista de que no había manera de entrar en arreglos con los colonos que reclamaban el derecho de propiedad a través de la posesión. ${ }^{36}$

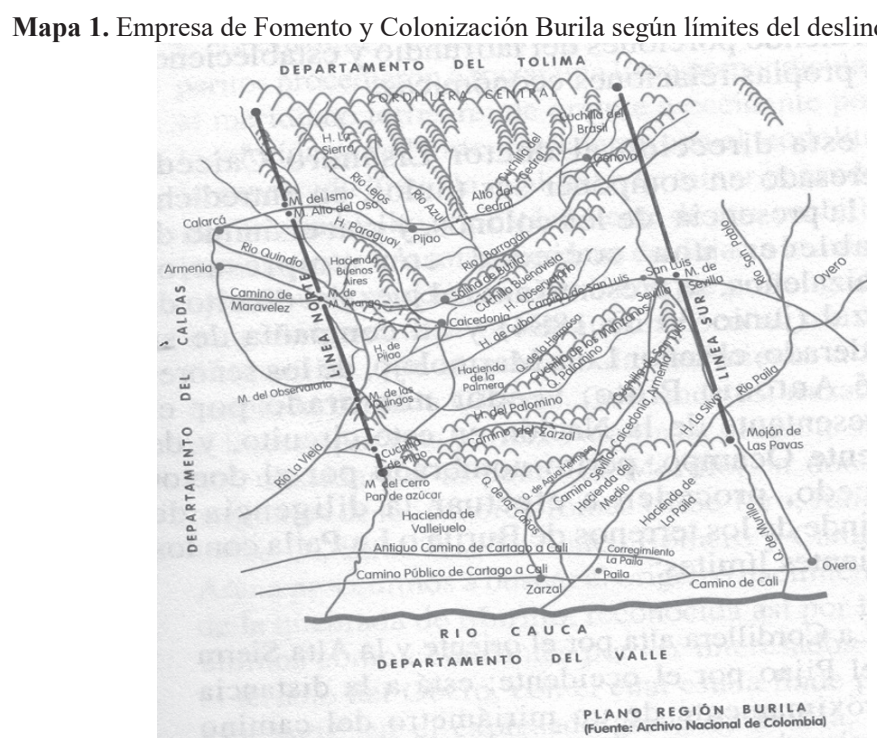

¿Cuál sería la relevancia de estas tensiones en relación con la propuesta analítica que hicimos inicialmente? Analizar el trámite que surtió el conflicto entre Burila y los colonos de Calarcá nos permite entender el proceso formativo del Estado en una región abierta a la colonización, en tanto ponen de manifiesto no solo la

\footnotetext{
${ }^{35}$ Según las escrituras de la empresa, la olla del Quindío prácticamente estaba en el globo reclamado según el deslinde inicial. AHM, Colombia,1884, Fondo Notaría, Escritura 693 del 25 de noviembre de 1884, páginas 210-211.

${ }^{36}$ Olga Cadena Corrales, Procesos de colonización en el Quindio.

${ }^{37}$ Albeiro Valencia, colonización, fundaciones y conflictos agrarios.
} 
fragilidad del discurso del Estado compacto y monopolizado por unas élites de poder, que para este caso sería el poder de Burila, sino que muestra la autonomía parcial de las unidades administrativas y las estrategias utilizadas por dichas unidades cuando los intereses de las burocracias se yuxtaponen.

Tengamos presente que Burila, como se mencionaba anteriormente, estaba constituida por figuras de la política nacional y regional; lo que podría llevarnos a creer que la empresa tenía alcances, incluso, en la planificación del territorio. Pero si bien es cierto, esto ocurrió, ${ }^{38}$ no quiere decir que la distribución administrativa del poder estatal no permitiera tener un contrapeso para las arbitrariedades promovidas por una o unas unidades de Estado.

\section{Burila y Calarcá, la disputa por las tierras baldías y el accionar político de las burocracias locales}

El pleito entre Burila y los colonos de Calarcá se desarrolló en una arena de tensiones y repertorios de acción política lideradas por ambos grupos a fin de garantizar el triunfo de sus intereses; por ello, el caso permite comprender cómo se iba construyendo el Estado en el territorio dado que, tanto las acciones como sus resultados, tuvieron como característica el uso e instrumentalización del discurso institucional y de la normativa existente. Por otra parte, los resultados obtenidos después de ejecutada las acciones permiten ver cuál era el alcance y cumplimiento en los territorios de la política pública en materia agraria y qué tanto, la gestión autónoma de poblaciones y burocracias locales, incidían en el alcance de sus intereses por vía formal e informal. ${ }^{39}$

Por otra parte, es importante tener presente que las tierras en disputa no se limitaban únicamente a Calarcá, puesto que la empresa englobaba otro vasto territorio hacia el sur, incluyendo en el mapa del conflicto a poblaciones como Génova, Colón (actual Pijao), Caicedonia y San Luis (actual Sevilla en el departamento del Valle del Cauca) $;{ }^{40}$ es por ello por lo que enfrentaban demandas sustentadas en la perturbación

\footnotetext{
${ }^{38}$ No es materia de este artículo ahondar en la forma como Burila diseñó el territorio aprovechando su poder político y la puerta giratoria con la que funcionarios del Estado se convertían en agentes de la empresa; sin embargo, sí podemos mencionar el caso del Fiscal delegado por el Gobierno nacional para el primer deslinde el cual tenía la función de garantizar que los bienes de la Nación no fueran vulnerados. Llama la atención entonces que, tres años después fuera el mismo funcionario, señor José Antonio Pinto, quien fungiera como abogado de Lisandro Caicedo ante la demanda interpuesta por el señor Pablo Gil por las perturbaciones a sus posesiones después del deslinde. Este caso se está desarrollando en la tesis doctoral que dio origen al presente artículo y reposa en el Archivo Histórico de Cartago, Colombia (AHC), 1884, Fondo judicial-república, Sección Demandas, Folio 221

${ }^{39}$ Se entiende por 'formal', los dispositivos legales para reclamar un derecho; así las cosas, hacer uso de memoriales, interponer una querella, adelantar una demanda y formalizar un predio, deben entenderse como repertorios de acción política 'formales', en tanto surgieron a partir de la planificación del proceso y se llevaron a cabo según los lineamientos institucionales. De todas maneras, no todas las acciones fueron desarrolladas en el marco del derecho de la época, puesto que hubo invasiones a terrenos no solo de Burila, sino también, de adjudicaciones adyacentes. Estos casos serán ampliados en la investigación doctoral que fundamenta este artículo.

${ }^{40}$ Véase, Wilder Andrés Carrero, "Conflictos y colonización en el Norte del Valle, el caso de Sevilla y la empresa Burila (1903-1930)”. (Tesis, Pregrado en Historia, Universidad del Valle, 2007).
} 
a una posesión. De todas formas, para Burila era más fácil pagar las mejoras de los colonos, que reconocer la titularidad de los predios ocupados antes del deslinde; además, se escudaban en la ratificación del fallo del Tribunal de Buga hecho por la Corte Suprema que validaba el deslinde de $1882,{ }^{41}$ obligándole únicamente a negociar con los cultivadores los trabajos de tumba y beneficio de los lotes, como también de sus posesiones.

De todas maneras, aunque los colonos y burocracias locales de Salento tenían conocimiento de dicho fallo y las estrategias jurídicas que usaba la empresa, nunca quitaron su respaldo a los cultivadores de Calarcá, como lo podemos corroborar en el memorial enviado por el Concejo Municipal y el Personero al Ministerio de Hacienda en el que denunciaban cómo Lisandro Caicedo se había aprovechado confundiendo los nombres de los linderos con los que estableció la línea norte de la compañía. En el memorial decían que

Llamamos cordillera de los Andes en nombre de Sierra de los Pijaos [a las tierras reclamadas por Caicedo, lo que le permitía] apropiarse de una superficie de terreno baldío que excede de cien mil hectáreas; [privando] así de un derecho de la nación y [privando] a los colonos de lo que les concede las leyes 61 y 48 sobre tierras baldías $[\ldots] .^{42}$

Este memorial, que además iba con copia a la Procuraduría General de la Nación y la Gobernación del Cauca, era el comienzo de una disputa no solo con los recursos que daban las leyes utilizadas durante los pleitos, sino también, la selección de funcionarios a los que debían comunicarse los hechos cotidianos y vejámenes alrededor de la colonización.

El Concejo Municipal y los colonos recurrían constantemente a la Ley 61 de 1874 y la 48 de 1882 . La primera era usada por los agentes favorables a los intereses de los cultivadores de Calarcá, por lo que manifestaban siempre que el Estado reconocía públicamente al colono en contra del presunto dueño al alegarse la posesión de buena fe; ${ }^{43}$ es decir que se refutaba a la empresa la propiedad de las tierras demarcadas en la escritura ya que había una posesión previa al deslinde.

Para el Concejo de Salento, el Personero y otras personalidades públicas del municipio, la ocupación de Calarcá contaba con el beneplácito de las instancias locales al considerarse que las tierras eran baldíos de la Nación, y si no lo fueran, de todas formas, la ocupación antecedía la misma reclamación que hacía Burila usando

\footnotetext{
${ }^{41}$ Este es el caso del mencionado señor Gil en contra de Burila por la perturbación de sus posesiones y la apropiación de los baldíos. Es menester tener presente que, para ese entonces, no existía el Tribunal de lo Contencioso administrativo, por lo que la ratificación que hizo la Corte permitía que los colonos demostraran, por vía judicial, que los asentamientos eran baldíos, más no entró a cuestionar el fallo del Circuito del Quindío que consideró legal el procedimiento de 1882 al contar con la presencia de un delegado del Gobierno nacional. El caso se puede seguir en AHC, Colombia,1884, Fondo Judicial-República, Sección Demandas, Folio 221.

${ }^{42}$ AGN, Colombia, 1889, Fondo Ministerio de Fomento, Sección República, Serie Baldíos, Volumen 1, Tomo II, Folio 112-116.

${ }^{43}$ AGN, Colombia, 1882, Diario Oficial N. 5457 del 31 de agosto, Ley 48 de 1882.
} 
escrituras con dudosa demarcación. El recurso jurídico que solían utilizar tenía como particularidad apoyarse en la Ley 61, pues según dicho postulado normativo, "todo individuo que ocupe terrenos incultos de la Nación, a los cuales no se les haya dado aplicación especial por la Ley, y establezca en ellos habitación y labranza, adquiere derechos de propiedad sobre el terreno que cultive, cualquiera que sea su extensión". ${ }^{44}$

Los colonos y sus aliados eran conscientes de que este recurso y el éxito durante el litigio estaba determinado por la capacidad de agenciar y moverse en el campo político. Sabían que las leyes les privilegiaban sobre cualquier otro interesado en títulos sobre un baldío y que los artículos constitutivos de la Ley legalizaban la ampliación de terrenos haciendo cercas, con un premio de 30 hectáreas más, siempre y cuando se tuvieran cultivos, casa y se llevara más de cinco años habitando allí. ${ }^{45}$

Por otra parte, la Ley también beneficiaba a los colonos debido a que descargaba la responsabilidad de su protección en los agentes de Estado a través de la vigilancia del cumplimiento de la normativa, y posteriormente, con la publicación del Decreto 518 de 1874, se especificó que los linderos y adjudicación de los baldíos eran en beneficio del cultivador primario, agregando las funciones del agrimensor, y en su artículo quinto, dejando claro que en conflicto de intereses

La autoridad política encargada de la administración del Distrito o Corregimiento a que corresponda la localidad, a solicitud verbal o escrita de cualquiera de los pobladores, hará comparecer ante ella a los individuos entre quienes se haya suscitado la disputa, y si no pudiere lograr que estos avengan amigablemente, procederá, previa inspección ocular del terreno, a demarcar provisionalmente los límites dentro de los cuales cada uno de los colonos pueden continuar sus trabajos. El funcionario encargado de hacer la demarcación dejará constancia, de todos los incidentes de ella en un expediente, que remitirá al Presidente o Gobernador del Estado o Prefecto del territorio para su aprobación [...] ${ }^{46}$

Como parte de los primeros resultados, producto de la presión política enviando memoriales como los mencionados anteriormente, el concejo de Salento y los colonos reclamantes lograron que el Gobierno del Cauca ordenara una inspección ocular en Calarcá (1890) en la que participaron el Prefecto de la Provincia del Quindío y el Personero Municipal de Salento. ${ }^{47}$ En dicha visita, los funcionarios reconocieron no solo que el poblamiento cumplía con los requisitos para la adjudicación de los lotes baldíos, sino que consideraron pertinente elevarlo a Corregimiento; además, la inspección delegó en la Junta Pobladora el derecho a seguir adjudicando lotes a quienes decidieran abrir la selva y ocupar los terrenos de Calarcá. Para tal diligencia, se consideró que la adjudicación consistía en:

\footnotetext{
${ }^{44}$ José Francisco Chaux, Memorias del Ministro de Industrias al Congreso de la República (Bogotá, Imprenta Nacional, 1931) 122.

${ }^{45}$ AGN, Colombia, 1884, Diario Oficial N. 3199, Ley 61 de 1874.

${ }^{46}$ José Francisco Chaux, 21.

${ }^{47}$ Jaime Lopera Gutiérrez. La colonización en el Quindio, apuntes para una monografía del Qiundio y Calarcá. (Bogotá: Banco de la República, 1986).
} 
Dar 32 hectáreas a cada varón casado y sin familia, y los casados y viudos con familia tendrán derecho a otras cinco hectáreas por cada hijo menor de veintiún años que tengan a cargo. [por otra parte, la comisión advertía a los pobladores que quedan sujetos a las siguientes obligaciones:

(a) fijar su residencia en el territorio de la población, (b) no enajenar la porción de terreno que se les adjudica, sin haber puesto antes en ella casa y una labranza que no baje de cuatro hectáreas; (c) a no enajenarla a persona que posea en la misma población más de cincuenta hectáreas de terreno; (d) a no darla dentro del término de cuatro años en pago de deuda alguna $[\ldots] .{ }^{48}$

Pasar de caserío a corregimiento era un importante avance administrativo puesto que formalizaba las nuevas ocupaciones; sin embargo, lo logrado por Calarcá no era suficiente pues los colonos reclamaban más tierras baldías, justamente las que la empresa seguía alegando poseer. Por ello el pleito, a pesar de haber dado un giro positivo para los colonos, no necesariamente terminó, sino que se mantuvo por varios años, especialmente después de que el corregimiento logró elevarse a municipio.

En cuanto a la segunda ley, es decir, la 48 de 1882, se usó debido a que mantenía legítima la ya mencionada 61 de 1874, pero precisaba que

En el juicio plenario de propiedad del terreno único admisible contra cultivadores de terrenos baldíos, establecidos en ellos con casa y labranza, el actor deberá exhibir los títulos legales de la propiedad de la tierra que reclama, que tengan una antigüedad de diez años, por lo menos, y en los cuales se expresen, con toda claridad, los linderos del terreno que reclama como suyo $[\ldots] .{ }^{49}$

A partir de 1890, en adelante, los pleitos fueron constantes; situación que se convirtió en un desgaste para ambos bandos, pero con especialidad para Burila, pues tendrían que demostrar que sus predios eran legalmente adquiridos y en caso de ganar ese pulso, pagar las mejoras de los ocupantes.

Fue por lo que, pronosticando una pérdida, Burila utilizó estrategias de desgaste para la Junta Pobladora y los colonos fundadores, fomentando la colonización con personas que desconocían el pleito y asignando lotes en la zona de disputa. De todas formas, desde Calarcá también se fomentaban acciones similares poniendo en tensión colonos contra colonos y trasladando el problema a terceros, por lo que, quienes tenían escrituras dadas por Burila, reclamaban la invasión de sus predios por aquellos que eran apoyados desde el municipio de Salento y la Junta Pobladora de Calarcá.

En 1904 los pobladores de Calarcá, con apoyo de Salento, solicitaron ante el Gobierno Nacional que el Corregimiento fuera reconocido como municipio, por lo que el resultado favorable de la solicitud se convirtió en uno de los principales golpes políticos a Burila, pues este reconocimiento implicó mayor autonomía para movilizar los intereses ante las instancias que fuesen pertinentes. Así Burila no solo enfrentaba

\footnotetext{
${ }^{48}$ Jaime Lopera Gutiérrez. La colonización en el Quindio, 107.

${ }^{49}$ José Francisco Chaux 149.
} 
a Salento, sino que ahora eran dos concejos municipales, con control político y económico que enfilaban baterías en contra de la empresa.

Puesto que la migración aumentaba, desde Salento se envió un memorial al Gobierno nacional con el fin de pedir la adjudicación de tierras para resolver prontamente la situación de aquellos colonos que tenían casas y cultivos, pero que finalmente no poseían títulos. El referido memorial pretendía que el Estado pusiera en consideración el caso y para ello exponían la situación personal y familiar de los colonos, los motivos que los había llevado a ocupar en Calarcá y las tensiones que tenían que vivir con la empresa Burila. Decía el memorial que:

Bien conocida es la intención del actual gobierno de proteger las industrias y principalmente la colonización pobre que es la que penetra á los bosques en búsqueda de sus riquezas y el porvenir de sus familias. Con las pretensiones previamente citadas se le causa gravísimos perjuicios a este vecindario porque se abarca una extensión no despreciable de territorios que sirve para su engrandecimiento y en el cual ya hay muchos colonos establecidos pero con los temores que más adelante ellos, o sus sucesores se expongan a controversias que dan por resultado la pérdida del fruto de sus trabajos en litigios de distintas clases que quizá no tendrían razón de ser [...]. ${ }^{50}$

Es menester tener presente que los colonos seguían contando con el respaldo del concejo municipal de Salento y, además, el de Calarcá, pero ahora utilizaban otra ley, la 56 de 1905 por medio de la cual se establecía que "todo individuo que ocupe tierras baldías y establezca en ella casa de habitación y cultivos artificiales, adquiere derechos de propiedad sobre el terreno cultivado y otro tanto". ${ }^{51}$ Además, según el señor Peña, presidente del Concejo de Calarcá, no era "conocido el título de propiedad de dicha sociedad la cual abarca una extensión considerable. Urge una resolución a fin de poder obrar con acierto". ${ }^{52}$

Como se trataba de presionar, ambos concejos y la Alcaldía de Calarcá, mantuvieron una correspondencia constante con los ministerios encargados; por ejemplo, Benjamín Palacios, alcalde de Calarcá, envió un telegrama al Ministro de Obras Públicas en el que mencionaba nuevamente la importancia de resolver el asunto de los planos de la municipalidad, y para ello decía que "para cumplir ley $(56)^{53}$ este año y hoy obligación de revisar planos por toda demarcación, o se excluyen las pruebas

\footnotetext{
${ }^{50}$ AGN, Colombia, 1905. Fondo Ministerio de Fomento, Sección República, Serie Baldíos, Tomo XXIV, Folio 351.

${ }^{51}$ José Francisco Chaux 216.

${ }^{52}$ AGN, Colombia, 1905. Fondo Ministerio de Fomento, Sección República, Serie Baldíos, Tomo XXIV, Folio 76.

${ }^{53}$ Esta Ley le encargaba a los Concejos municipales la autoridad para adjudicar predios, dejando una puerta abierta para la corrupción; de allí que pronto tuviera que ser derogada. De todas formas, la mencionada Ley 56 sería transitoria por su ambigüedad, especialmente para resolver casos como el de Burila y Calarcá. En dicha normativa se permitía que los concejos municipales adquirieran jurisdicción administrativa sobre las adjudicaciones reservando la discrecionalidad a ellos pero no se lograba resolver si aplicaba para adjudicaciones de menor cuantía o para todo tipo de adjudicación.
} 
pasen cien (100) hectáreas conforme a disposiciones anteriores, pero observando prescripciones científicas". ${ }^{4}$ También enviaban misivas a la Gobernación del Cauca pidiendo que los colonos no tuvieran que pasar por las distintas instancias y rituales de las adjudicaciones, pues estos eran muy pobres. Decía la respectiva carta que

a. En atención al número de vecinos y a la inmigración de ciudadanos con sus familias, dígnese acatar nuestra solicitud y dispongais [sic] concesión o reglamento para distribuir la riqueza mas sin las ritualidades actuales por que es imposible cumplirlas por la desastrosa situación económica y otras causas.

b. Como lo deseamos cesarán los disturbios, dejará la policía de resolver cuestiones que no hacen tránsito a cuestión juzgada, se acabarán los deslindes provicionales [sic] que no constituyen propiedades y cada uno sabrá en firme lo que tiene $[\ldots] .{ }^{55}$

La segunda estocada contra Burila se dio el 15 de junio de 1907 con la emisión de la Ley 36 de 1907, por medio de la cual el Estado reconocía el dominio de Calarcá sobre los baldíos ocupados por los colonos, cediendo un importante globo de tierra con sus respectivos linderos, y desestimando las reclamaciones de Burila, a pesar de que esta se sustentara en escritura pública. ${ }^{56}$ Posteriormente, a través de Resolución emanada del Ministerio de Obras Públicas y Fomento, publicaba en el Diario Oficial número 13168 de 14 de enero de 1908, se exponía la reglamentación para adjudicar a los colonos los terrenos cedidos al municipio.

El cierre de este pleito es interesante debido a que la Ley 36 entregó 60.400 hectáreas al área de la población, de las cuales 400 serían medidas y levantadas en plano, y también estableció que el concejo sería el máximo garante de justicia sobre las adjudicaciones, por lo que delegaba en el alcalde la potestad de crear la lista de pobladores para la respectiva adjudicación. ${ }^{57}$ De esta manera se cerró una parte del conflicto, aunque Burila siguió fomentando colonizaciones y creación de Juntas Pobladoras cercanas a sus intereses; este es el caso de Colón, actual municipio de Pijao, y que llevó a un nuevo conflicto entre Calarcá y la empresa. ${ }^{58}$

\section{Conclusiones}

La disputa por los terrenos baldíos comprendidos en las Escrituras de Burila y reclamados por los colonos de Calarcá, quienes contaban con el respaldo

\footnotetext{
${ }^{54}$ AGN, Colombia, 1905. Fondo Ministerio de Fomento, Sección República, Serie Baldíos, Tomo XXIV, Folio 22. ${ }^{55}$ AGN, Colombia, 1905. Fondo Ministerio de Fomento, Sección República, Serie Baldíos, Tomo XXIV, Folio 26.

${ }^{56}$ José Francisco Chaux 240.

${ }^{57}$ José Francisco Chaux 255.

${ }^{58}$ El caso de Colón es interesante puesto que fue Daniel Gutiérrez Arango, gerente de Burila, quien impulsó la creación del municipio desde 1905, generando una lluvia de críticas y memoriales por parte de Calarcá, quien alegaba la ilegalidad del acto puesto que la población se estaba fundando al interior de los terrenos adjudicados a Calarcá por la Ley 36 de 1907. Este caso puede ampliarse en Wilder Andrés Carrero, Los procesos de formación estatal, 201-209.
} 
del Concejo Municipal de Salento y algunos servidores públicos como el personero municipal, nos permitió identificar los problemas más comunes de la colonización en el Quindío y por qué no, de otras regiones del país; pues no es secreto que la vastedad del territorio facilitó la confusión de los linderos mezclando tierras públicas y privadas, exacerbando las tensiones sociales y demostrando la poca capacidad estatal para defender los baldíos. Paradójicamente, la ausencia de límites territoriales que definan la ubicación de las tierras públicas y privadas sigue siendo uno de los principales problemas agrarios en Colombia.

Ahora bien, la adjudicación de las 60.400 hectáreas no resolvió el conflicto en su totalidad, puesto que, en la línea sur, Burila siguió fomentando la colonización y disputando con Calarcá el control de caseríos como Génova o Colón, actual Pijao en el Quindío. Por otra parte, la adjudicación de lotes en las 400 hectáreas de la cabecera municipal llevó a otro tipo de conflictos, esta vez entre la Junta Pobladora y los colonos que llegaron buscando una propiedad durante la repartición de los solares.

Por otra parte, es menester resaltar que la transformación del conflicto estuvo determinada por la capacidad de movilización política de los actores vinculados en los pleitos; ahora bien, esta experiencia permite discutir la visión clásica del Estado como un cuerpo compacto, abriendo la posibilidad de estudiar el Estado desde la capacidad de autonomía que tienen sus unidades políticas, puesto que fue la gestión y liderazgo de las burocracias locales y los colonos de Salento y Calarcá, lo que permitió, incluso, operar en contravía al fallo del tribunal usado por Burila para amedrentar a quienes reclamaran derechos de posesión sobre el baldío.

Esta experiencia nos permitió pensar el Estado más allá desde una perspectiva procesual, resaltando que su formación no es únicamente vertical; es decir que la materialización de sus políticas en el territorio no son producto de una decisión arbitraria que se emite desde el centro, sino que también es horizontal y tiene discontinuidades, de allí que la cristalización de una política de Estado dependa de cómo se tramite en los territorios. Evidentemente, las autoridades centrales no tenían conocimiento de las prácticas que se llevaban a cabo en la zona en disputa, y su alcance era el dado por los fallos judiciales y solo a partir de una presión insistente por parte de las burocracias de Salento y Calarcá, fue que se logró un fallo administrativo a favor de la población. Esta es una de las razones por las cuales debe hablarse del proceso formativo del Estado como algo multiforme y discontinuo.

En el caso estudiado, también se pudo ver que la participación del Estado varía dependiendo del momento histórico y la unidad con la que interviene en los conflictos, puesto que la intervención de sus unidades centrales tuvo matices que estuvieron determinados por discurso dominante y la medición de fuerzas con los actores del conflicto. También se evidencia que el discurso estatal tuvo contradictores al interior de las unidades, de allí que el concejo municipal y la personería actuaran en representación de los pobladores y asumiera una posición contraria a las disposiciones de jerarquías superiores como los juzgados del circuito, la Gobernación del Cauca y los mismos ministerios públicos involucrados en la contienda. 
Finalmente consideramos que para ampliar la discusión, es importante acceder a más fuentes primarias; en este caso sería pertinente consultar las actas de junta de la empresa Burila y las actas de las sesiones del Concejo Municipal de Salento y Calarcá, como también, profundizar en los pleitos llevados en los juzgados que atendieron a los colonos. Por otra parte, es importante hacer un seguimiento a las ventas hechas por Burila durante la colonización del Quindío y el norte del Valle del Cauca, pues esto nos permitirá conocer cómo variaban los costos de la propiedad y cómo afectó el conflicto a los titulares de los predios en disputa.

\section{Bibliografía}

\section{Fuentes primarias}

\section{Archivos}

Archivo General de la Nación, Colombia (AGNC), 1882, Diario Oficial N. 5457 del 31 de agosto, Ley 48 de 1882.

Archivo General de la Nación, Colombia (AGNC), 1884, Diario Oficial N. 3199, Ley 61 de 1874.

Archivo General de la Nación, Colombia (AGNC), 1889, Fondo Ministerio de Fomento, Sección República, Serie Baldíos, Volumen 1, Tomo XI, Folio 111.

Archivo General de la Nación, Colombia (AGNC), 1889, Fondo Ministerio de Fomento, Sección República, Serie Baldíos, Volumen 1, Tomo II, Folio 112-116.

Archivo General de la Nación, Colombia (AGNC), 1905. Fondo Ministerio de Fomento, Sección República, Serie Baldíos, Tomo XXIV, Folio 351.

Archivo General de la Nación, Colombia (AGNC), 1905. Fondo Ministerio de Fomento, Sección República, Serie Baldíos, Tomo XXIV, Folio 76.

Archivo General de la Nación, Colombia (AGNC), 1905. Fondo Ministerio de Fomento, Sección República, Serie Baldíos, Tomo XXIV, Folio 22.

Archivo General de la Nación, Colombia (AGNC), 1905. Fondo Ministerio de Fomento, Sección República, Serie Baldíos, Tomo XXIV, Folio 26.

Archivo General de la Nación, Colombia (AGNC), 1906, Diario Oficial N. 12621 del 18 de abril. Decreto ejecutivo 27 de 1906.

Archivo General de la Nación, Colombia (AGNC), 1907, Diario Oficial N. 12986 del 27 de junio, Ley 36 de 1907. 
Archivo Histórico de Cartago, Colombia (AHCC), 1884, Fondo Judicial-República, Sección Demandas, Folio 221.

Archivo Histórico de Cartago, Colombia (AHCC), 1884, Fondo judicial-república, Sección Demandas, Folio 221.

Archivo Histórico de Manizales, Colombia (AHMC), 1884, Fondo Notaría, Escritura 693 del 25 de noviembre de 1884, páginas 210-211.

Archivo Histórico de Manizales, Colombia (AHMC), 1884, Fondo Notaría, Escritura 693 del 25 de noviembre de 1884, páginas 210-211.

Archivo Histórico de Manizales, Colombia (AHMC),1884, Fondo Notaría, Escritura 693 del 25 de noviembre de 1884, páginas 210-211.

Archivo Histórico José María Arboleda y Llorente, de la Universidad del Cauca, Colombia (AHJML1C), 1878, Fondo Archivo inactivo, Sección República, Caja 145, Legajos 65-68.

\section{Fuentes secundarias}

\section{Libros}

Acuña, Carlos H. (Compilador). Lecturas sobre el Estado y las políticas públicas: retomando el debate de ayer para fortalecer el actual (Buenos Aires: Gobierno de Argentina, 2007).

Appelbaum, Nancy. Dos plazas y una nación: Raza y colonización en Riosucio, Caldas, 1846-1948, (Bogotá: Instituto Colombiano de Antropología e Historia ICANH, Universidad de los Andes, Universidad del Rosario, 2007).

Arent, Hanna. ¿Qué es la política? (Barcelona: Paidós, 1997).

Buitrago, Jaime. Hombres trasplantados, novela de colonizaje (Biblioteca de autores quindianos, 2011).

Carrero, Wilder Andrés. Los procesos de formación estatal en Colombia vistos a través de la colonización y las prácticas políticas en el Quindio (1884-1930) (Pereira: Universidad Tecnológica de Pereira, 2018).

Chaux, José Francisco. Memorias del Ministro de Industrias al Congreso de la República (Bogotá, Imprenta Nacional, 1931).

Larrichio, Larry Vito. La construcción multicultural de una economía colonial: cambio demográfico y organización del trabajo en el Valle medio del río Cauca, siglo XVIII (Pereira, Universidad Tecnológica de Pereira, 2018). 
La disputa política entre Calarcá-Quindio y la empresa de Fomento y Colonización Burila...

Lopera Gutiérrez, Jaime. La colonización en el Quindio, apuntes para una monografía del Qiundio y Calarcá (Bogotá: Banco de la República, 1986).

Molina, Alonso. El despliegue del Estado en el poblamiento de la Montaña del Quindio y la fundación de Santa Rosa de Cabal, 1840-1845 (Pereira, Universidad Tecnológica de Pereira, 2019).

Ortiz Mesa, Carlos Miguel y otros. Caldas, una región antigua y nueva, tradicional y moderna, local y nacional: hacia un nuevo Siglo XIX del noroccidente colombiano. Balance bibliográfico de Antioquia, Caldas y Chocó, Tomo 2, Coord., Luis Javier Ortiz (Medellín: Universidad Nacional de Colombia, 2015).

Valencia, Albeiro. Colonización, fundaciones y conflictos agrarios (Manizales: Artes Gráficas Tizán, 2000).

\section{Capítulos de libros}

Bourdieu, Pierre F. "Clase del 18 de enero de 1990”. Sobre el Estado: cursos en el Collège de France (1989-1992) (Barcelona: Anagrama, 2014).

González, Fernán E. "El proceso de formación estatal en Europa e Iberoamérica". Estado y poder en Colombia (Bogotá: Odecofi, 2014).

Oszlak, Óscar y O`Donnell, Guillermo. "Estado y políticas estatales en América latina: hacia una estrategia de investigación". Lecturas sobre el Estado y las politicas públicas: retomando el debate de ayer para fortalecer el actual. Comp. Carlos $\mathrm{H}$. Acuña (Buenos Aires: República de Argentina, 2007).

Weber, Max. "Conceptos sociológicos fundamentales". Economía y Sociedad (Barcelona: Fondo de Cultura Económica, 1974) 127-130.

\section{Artículos de revistas}

Cadena, Olga. "Impacto de la compañía Burila en el Quindío". Voces, Revista de estudios sociales 3 (1997): 57-70.

Londoño, Jaime. "El modelo de colonización antioqueña de James Parsons. Un balance historiográfico". Fronteras de la historia, revista de historia colonial latinoamericana 7 (2002):187-228.

\section{Tesis, ponencias y otros inéditos}

Cadena, Olga. "Procesos de colonización en el Quindío: el caso de Burila" (Tesis, Maestría en Historia, Universidad Nacional de Colombia, 1988).

Carrero, Wilder Andrés. "Conflictos y colonización en el Norte del Valle, el caso de Sevilla y la empresa Burila (1903-1930)". (Tesis, Pregrado en Historia, Universidad del Valle, 2007). 
Mann, Michael. "The crisis of the Latin American Nation-Satate, The political crisis and internal conflict in Colombia Abril 10-13, (Bogotá: Uniandes, 2002).

Tobasuña, Isaías. "Del altiplano cundiboyacense al páramo de letras (caldas). Algunos aspectos socioculturales del proceso" (Ponencia, II simposio de Historia Local y Regional, Academias y Universidades, Universidad Tecnológica de Pereira, 2007).

Wills, María Emma. "Los tres nudos de la guerra colombiana: un campesinado sin representación política, una polarización social en el marco de una institucionalidad fracturada, y unas articulaciones perversas entre regiones y centro". Centro Nacional de Memoria Histórica.

\section{Publicaciones en internet}

Calarcá.Net, https://www.calarca.net/enlamano.html (2019). 